\title{
Design and Testing of an Ultrasound System for Targeted Spraying in Orchards
}

\author{
Viktor Jejčič ${ }^{1}$ - Tone Godeša ${ }^{1}$ - Marko Hočevar ${ }^{2}$ - Brane Širok ${ }^{2}$ - Aleš Malneršič̌ ${ }^{2}$ - Andrej Štancar ${ }^{3}$ - \\ Mario Lešnik ${ }^{4}$ - Denis Stajnko 4 ,* \\ ${ }^{1}$ Agricultural Institute of Slovenia, Slovenia \\ 2University of Ljubljana, Faculty of Mechanical Engineering, Slovenia \\ ${ }_{3}^{3}$ University of Ljubljana, Faculty of Computer and Information Science, Slovenia \\ ${ }^{4}$ University of Maribor, Faculty of Agriculture and Life Sciences, Slovenia
}

The research aims to demonstrate the basic system elements of a prototype automated orchard sprayer, which can deliver pesticide spray selectively with respect to the characteristics of the targets. The contour of the apple tree canopy was detected by ultra sound sensors Prowave 400EP14D and appropriate electronics. Ultra sound signal was processed by a personal computer and fed in real-time to spraying nozzles which open and close in relation to the canopy structure. The current project focuses on developing the system components for spraying an individual tree. The evaluation was performed in field experiments by detecting deposits on leaves and water sensitive papers (WSP). The demonstrated concept of precise application of pesticide sprays supports a decrease in the amount of delivered spray, thereby reducing both costs and environmental pollution by plant protection products.

(C)2011 Journal of Mechanical Engineering. All rights reserved.

Keywords: air-assisted sprayer, ultra sound, algorithm, spray distribution, orchard

\section{INTRODUCTION}

Apple fruit orchards are sprayed mainly with axial fan 'mistblower' orchard sprayers, because the fan is effective in a wide range of orchard types and under a wide range of conditions. These sprayers are simple, robust, reliable and of a comparatively low cost in terms of purchase and operation. Unfortunately, the large radial spray plume generated by axial fan orchard sprayers is prone to spray drift, thus large losses to the atmosphere and ground occur [1] and [2]. Possibilities of adapting the characteristics of air stream generated by axial fan sprayer to different tree canopies are quite limited.

A number of systems for adjusting the applied dose of plant protection products according to orchard structure have been developed in the past decades. One widely accepted is the Tree Row Volume $(T R V)$ dosing system initiated by [3]. In this system, the dose applied to an orchard is varied by varying the spray volume at constant pesticide concentration in proportion to the $T R V$. The $T R V\left(\mathrm{~m}^{3} \mathrm{ha}^{-1}\right)$ is the volume of the tree canopy per unit of ground area $(=10000$ $\times$ crown height $\times$ crop width / row spacing). The $T R V$ spray volume adjustment system has been adapted and tested for low volume spraying in several European countries [4] to [6]. In contrast to the TRV model, [7] and [8] proposed the use of leaf area measurements to improve the correlation between deposits given by different types of spraying equipment and types of hedgerow vineyards. However, different shapes and sizes of tree canopies, even among the same variety in the orchard, require continual calculation of $T R V$ and adjustment of the applied dose of pesticide to optimize the spray application efficiency [9].

It is for these reasons that in the last 10 years measurement of crop structure has been simplified by the development of a range of non-invasive optical and ultrasonic sampling techniques. In particular, the development of a compact, tractor-mounted light and range detection system (LIDAR) has made it possible to take quick and detailed readings of crop structure [10]. These are suitable for computational processing to calculate a wide range of summary parameters based on a probabilistic interpretation of light transmission and crop interception characteristics [11]. Such a system employs a pulse time-of-flight ranging method, with separate apertures (side-by-side) for an infrared laser diode transmitter and a matched diode light receiver. 
Contrary to the expensive radar system, [12] suggested the use of ultrasonic sensors and proportional electro-valves with the corresponding software and automation, which allowed real time modification of the sprayed flow rate adapted to the crop structure of the vineyard. In response to changes in the shape and size of the vines during the growing season, this system reduced the spray volume and the use of pesticides by up to $57 \%$, while maintaining coverage and penetration rates similar to those from conventional spraying methods.

However, since the ultrasonic sensors were originally designed to measure distances in industrial environments, where objects are rigid, and the surface of rebound is perpendicular to the direction of the ultrasonic wave, their utility in orchard measuring might be negligible [5]. Some of the deficiencies of standard sensors can be overcome by modern sophisticated ultrasound signal processing algorithms.

The purpose of our research was to develop an automated orchard sprayer consisting of an axial fan with nozzles controlled by an ultrasound processing system. The results of experiments in the apple orchard and comparisons of spray coverage characteristics as well as the savings of spray between two working modes (with and without automated guidance) are presented in the following sections.

\section{METHODOLOGY}

\subsection{General Experiment Information}

The spray distribution and coverage measurements presented are the outcome of experiments carried out in the research orchard of Brdo pri Lukovici (4610'N, 14040'E), owned by the Agricultural Institute of Slovenia. Spraying without using ultrasound guidance (control spraying mode, CM) was compared with a novel spraying method using prototype ultrasound sprayer guidance (automated spraying mode, AM). The configuration of the sprayer is explained in full details in section 1.2.

The experiments were performed on spindle trained 4-year old 'Gala' apple trees, shown in Fig. 1a, which were grafted onto M9 rootstock and planted at $0.7 \mathrm{~m}$ inter tree spacing and an inter row spacing of $3.2 \mathrm{~m}$. The average height of the trees was $2.5 \mathrm{~m}$. A continuous oneside spraying of trees along the tree row was performed from both sides of the row. Within trees in the sprayed row, five trees and three inter-tree spaces were selected for an analysis of spray coverage and deposit. Each tree (Figs. 1b, and 2) represented one statistical repetition of experimental measurements, with 9 positions ( $\mathrm{P} 1$ to $\mathrm{P} 9$ ) analysed in the canopy and 3 positions (P10 to P12) between trees.

a)

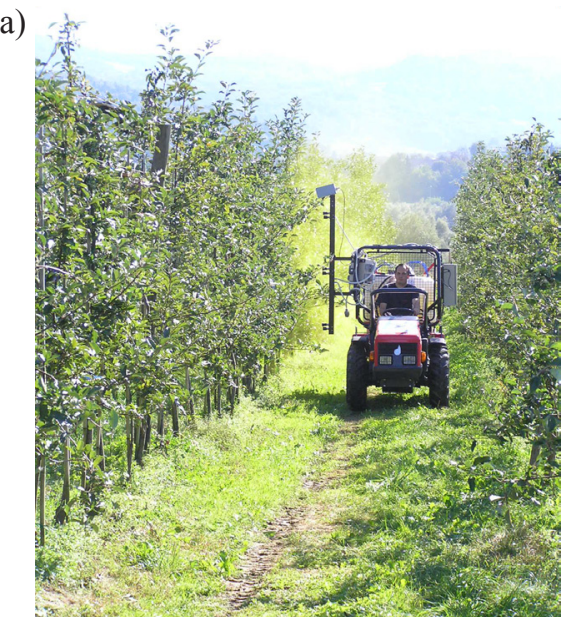

b)

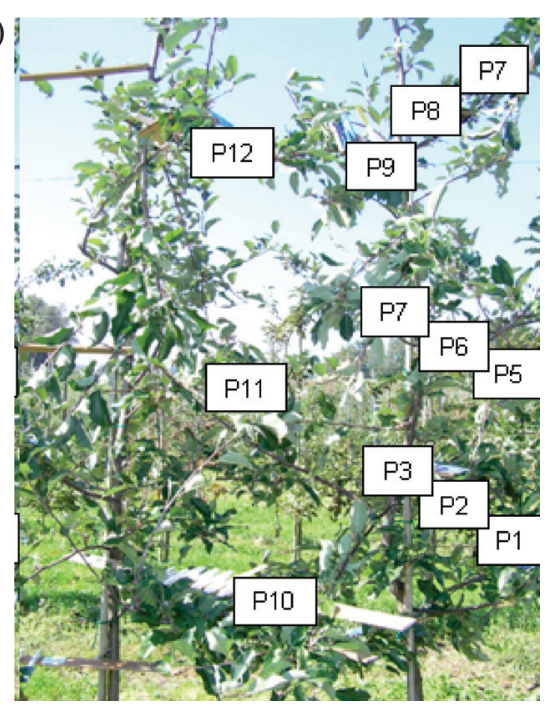

Fig. 1. a) A prototype sprayer during the experiment in the orchard; b) detail with measuring positions on the tree

The positions on the tree were selected according to: 


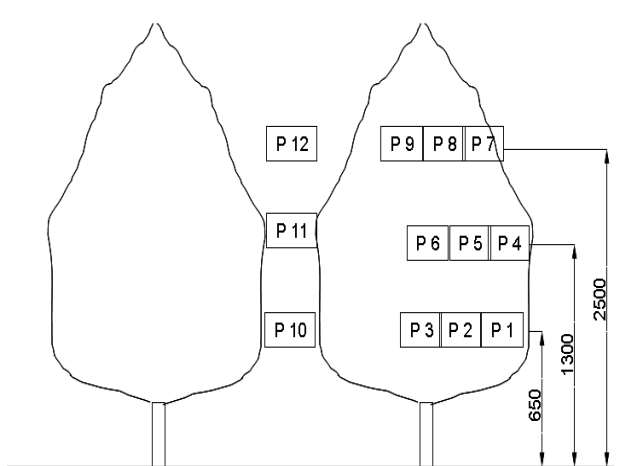

Fig. 2. Measuring positions on the tree and between trees

a) depth: at distance of $10 \mathrm{~cm}$ from the exterior (P1, P4, P7), in the middle at $30 \mathrm{~cm}$ from the centre of the trunk (P2, P5, P8), and behind the tree trunk (P3, P6, P9);

b) position on the tree: P1 to P3 were placed in the lower part of the tree height $(650 \mathrm{~mm}), \mathrm{P} 4$ to $\mathrm{P} 6$ in the centre of the tree $(1300 \mathrm{~mm})$ and P7 to P9 in the top part of tree height (2500 $\mathrm{mm})$.

Additional three positions (P10 to P12) for measuring deposits between tree positions were selected according to the height; lower P10 (650 $\mathrm{mm}$ above the ground), middle P11 (1300 mm above the ground) and the top P12 (2500 mm above the ground).

The experiment was arranged in a single row, from which a $63.76 \mathrm{~m}$ long part was selected to ensure constant guiding and meteorological conditions. Any passing to other tree rows would immediately cause additional variability. During the tests the following values for the meteorological conditions were recorded: temperature 16.9 to $21.2{ }^{\circ} \mathrm{C}$, relative humidity 68.8 to $74.8 \%$, wind speed 1.2 to $1.8 \mathrm{~ms}^{-1}$ and wind direction 18 to $40 \mathrm{deg}$ deviation from perpendicular direction of the sprayer track.

\subsection{Sprayer}

The prototype sprayer was developed by modification-upgrading of a mounted airassisted sprayer AGP 200 (Agromehanika Kranj, Slovenia), equipped with a piston pump and a 200 1 tank, a pressure-limiting valve, a blower unit with an axial fan and a nozzle boom around the air outlet (Fig. 3).

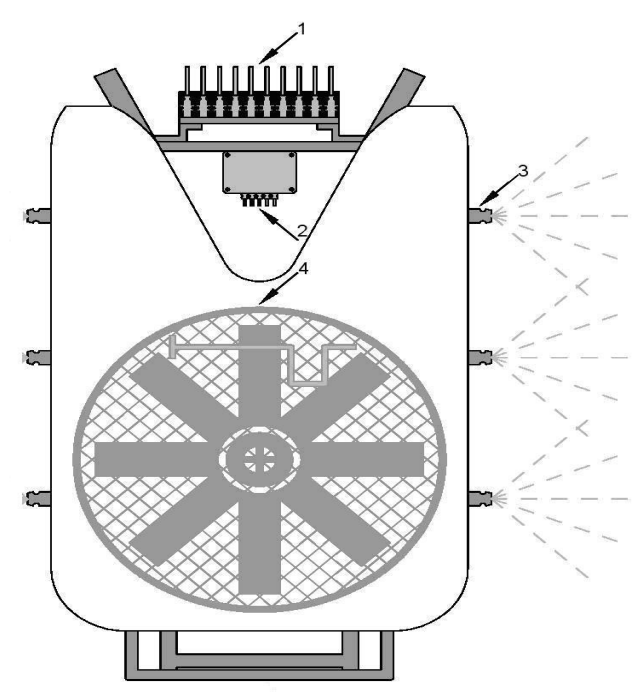

Fig. 3. A prototype mounted air-assisted sprayer; 1) electro-hydraulic valves, 2) electricity box, 3) operating nozzle- left nozzles closed during the experiment, 4) axial fan

The prototype was fully operative on one side. There were 3-nozzle sections with one electric valve mounted in each one. Three ultrasonic sensors were placed $280 \mathrm{~cm}$ in front of the nozzle plane in the direction of travel, at 60 , 120 and $200 \mathrm{~cm}$ above the ground (Fig. 4).

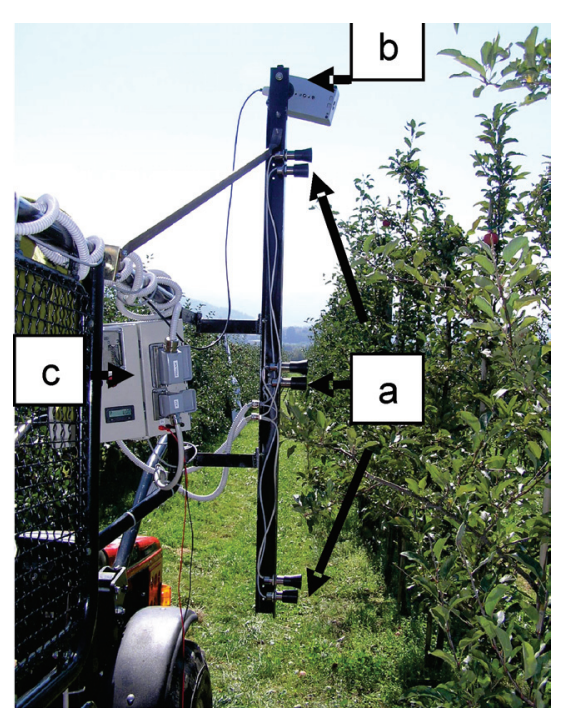

Fig. 4. Position of a) ultra sound sensors with horns and b) RGB camera; c) electric box contains tachometer unit with display and power electronics to control the valves 
Each sensor commanded one electrovalve. At the same time a bypass valve in the sprayer manifold allowed the prototype to work as a conventional sprayer to be used as reference in the field tests.

To avoid spraying at too low pressures, an anti-drip device was mounted on each nozzle with an internal spring set to open at 1.5 bar. These devices also helped to shorten response times by keeping the pipes full, ready to spray when the pressure exceeded the one set with the springs.

The position of the spraying nozzles in both modes is presented in Fig. 3. As seen, the first bottom nozzle was set at a height of $60 \mathrm{~cm}$, the middle one at $90 \mathrm{~cm}$ and the top one on 120 $\mathrm{cm}$. Each nozzle sprays within 80 to $90^{\circ}$ angle, therefore it covers a height of about $1 \mathrm{~m}$ of tree crown, if each nozzle is orientated perpendicularly to the tree green wall and the nozzles are positioned around $0.5 \mathrm{~m}$ from the edge of tree crown. In our case with three nozzles, this was enough to cover a $2.5 \mathrm{~m}$ high tree crown, when assuming that the lowest $40 \mathrm{~cm}$ zone was not sprayed and neighbouring sprays slightly overlap.

All three nozzles of the sprayer were opened in the CM all the time and none of the three sprayer sections were controlled by a guidance system, as it is the case with standard radial sprayers already in use. On the other hand, during the AM opening or closing of nozzles was controlled online by ultrasound acquisition and analysis system.

\subsection{Operational Conditions of the Orchard Sprayer}

The spraying was performed at forward speed of $0.83 \mathrm{~ms}^{-1}\left(3.00 \mathrm{~km} \mathrm{~h}^{-1}\right)$ for both spraying modes. Characterization of the air stream was obtained with a vane anemometer Schiltknecht MiniAir20 with $22 \mathrm{~mm}$ vane. To ensure proper sampling, air velocities were measured for each of three air outlet zones separately in an axial horizontal direction, $500 \mathrm{~mm}$ apart from the outlets and the nozzles where the air jet was wider than the diameter of the anemometer sample volume $(100 \mathrm{~mm})$. For all tests, the PTO rotational speed was $540 \mathrm{~min}^{-1}$. This gave a mean air volumetric flow rate of $2.90 \mathrm{~m}^{3} \mathrm{~s}^{-1}$ and a mean air velocity of $10.8 \mathrm{~ms}^{-1}$. The sprayer was equipped with three hollow cone nozzles (Lechler TR yellow) operating with a pressure drop of $10.0 \mathrm{bar}$, to give total spray flow rates of 4.351 $\mathrm{min}^{-1}$. Thus, the maximum range of values for the applied spray volume per unit of ground area was 2901 ha $^{-1}$, when all the nozzles were opened. The sprayer settings (Table 1) were the same for both operating modes.

The pump used was a four piston semihydraulic diaphragm pump model (BM 65/30, Agromehanika, Slovenia) with volume flow 601 $\min ^{-1}$ at a selected rotational speed $540 \mathrm{~min}^{-1}$.

\subsection{Control System for Executing the Sensor Guidance of Nozzles}

For the control of the sprayer in the AM the nozzles were opened and closed based on presence or absence of targets, sensed by ultrasonic transceivers. This procedure is explained in more detail below.

System operation included the triggering of ultrasonic transceivers, a calculation of distance using transceivers' own electronics, processing and time delaying of data from transceivers, and turning on/off valves for pesticides dosage. Same transceivers were used for sending and receiving. The triggering of transceivers was used to prevent unwanted false detections that could arise from the signal being detected on the selected transceiver immediately after another transceiver produced a sound burst.

System control was provided by a control unit consisting of a personal computer (PC), two 16 bit multipurpose data acquisition boards with counter I/O, a colour industrial fire wire IEEE 1394 camera and appropriate software for data and image acquisition, processing and data storage on disk. Control system was protected and mounted to the electric box on the left side of the tractor behind the driver (Fig. 1a). The PC was an embedded fan less computer IEI ECK - 3692 G with Intel Core 2 Duo $1.66 \mathrm{GHz}$ processor with $\mathrm{SSD}$ data storage drive. For transceiver triggering and data acquisition USB data acquisition units NI 6112 and NI 6110 were used, each with analogue and digital inputs and outputs and two independent 32 bit counters. 
Table 1. Operational parameters during treatments

\begin{tabular}{|c|c|}
\hline & $\begin{array}{c}\text { Operational } \\
\text { parameters }\end{array}$ \\
\hline Nozzle serial number & Lechler TR $80-02$ \\
\hline Colour & Yellow \\
\hline $\begin{array}{c}\text { No. of active nozzles per } \\
\text { side }\end{array}$ & 3 \\
\hline Pressure [bar] & $0-1.45$ \\
\hline $\begin{array}{c}\text { Spray flow rate per nozzle } \\
{\left[1 \text { min- }^{-1}\right]}\end{array}$ & $0-4.35$ \\
\hline $\begin{array}{c}\text { Spray flow rate all nozzles } \\
{\left[1 \text { min }^{-1}\right]}\end{array}$ & 3 \\
\hline Forward speed [km $\left.\mathrm{h}^{-1}\right]$ & 3.0 \\
\hline Working width [m] & 290 \\
\hline $\begin{array}{c}\text { Reference application rate } \\
{\left[1 \text { ha }^{-1}\right]}\end{array}$ & 540 \\
\hline PTO speed [rev min $\left.{ }^{-1}\right]$ & 2.90 \\
\hline $\begin{array}{c}\text { Volumetric air flow rate } \\
{\left[\mathrm{m}^{3} \mathrm{~s}^{-1}\right]}\end{array}$ & \\
\hline
\end{tabular}

Ultrasonic transceivers used were Prowave 400EP14D with SRM 400 sonar ranging module electronics. The sensors were equipped with a horn with $25 \mathrm{~mm}$ length and $22^{\circ}$ angle (Fig. 4). For triggering digital outputs from the control system were used. When ultrasonic transducers received the trigger input, they output a $5 \mathrm{~ms}$ tone burst of ultrasound at $44 \mathrm{kHz}$ with bandwidth of $1.5 \mathrm{kHz}$ at $-6 \mathrm{~dB}$. Amplification of output signal included band pass filtering with temperature compensation.

A short period after the tone burst was sent, the transceiver was inactive to allow transceivers' oscillation to damp out. Then, transceivers switched to listening mode. The received signal was band pass filtered and amplified with a fixed first stage amplifier and later with a second stage variable rate amplifier. The variable rate amplifier used 32 steps, where the first received signals were amplified less and later the received signals more. The variable amplifier compensated for the reduction of intensity of received signal, which attenuates with increased time elapsed from output tone burst, corresponding to larger distances. The transceivers' electronics checked for a threshold in returned signal; if the amplified echo signal from the output of the band pass filter exceeded $0.35 \mathrm{~V}$, the comparator output a low output pulse. In such case, for the time of duration of the low output pulse, a pulse width modulation PWM type of output was generated. For PWM output, the time between the tone burst output and the threshold received signal is a measure of distance of object in the transceivers view, while the presence of PWM output also denotes the presence of the target. The sensors were configured in such a way that the operational range was from 25 to $150 \mathrm{~cm}$. The frequency of the acquisition of distance of sensors from targets was $300 \mathrm{~ms}$ for three sensors. This time corresponded to $90 \mathrm{~cm}$ of tractor movement.

The duration of output PWM signal was measured using counters on data acquisition boards. PWM signals were accepted as valid to indicate presence of the plant canopy structures, if distance to the target was from 50 to $110 \mathrm{~cm}$. With such an approach, the number of leaves and density of the canopy were not distinguished by different PWM signal characteristics. The measured duration of PWM signal was delayed to compensate for the required time that the sprayer and pesticide spray need to reach the target. Time delay was fixed; therefore sprayer velocity was maintained constant. This was done manually by the driver who had available information about the tractor velocity from an inductive sensor mounted on the wheel and connected to tachometer unit with display as seen in Fig. 4. The signal from the control unit required to turn on the valves for pesticide dosage was provided by digital outputs on data acquisition boards through mosfet output power transistors. For the control of spray flow through the nozzles, output was connected to direct-acting solenoid valves $2 / 2 \mathrm{NC}$ 1/4 21A2KV25, coil code RBDA08024AS 8W $24 \mathrm{~V} / 50 \mathrm{~Hz}$ (ODE, Italy).

For later analysis of spray savings, simultaneously with information from distance transceivers, images of the target were acquired. The images were used only to detect positions, on which spray deposit was measured and to check spray nozzles open/closed status on the same positions. Flea2 color camera from Pointgrey Research Camera with $5.6 \mathrm{~mm}$ C-mount megapixel lens (Fig. 4) was used. The camera was connected to the computer using the fire wire IEEE 1394 connection. The resolution was $1024 \times 768$ pixels. The images were acquired with $30 \mathrm{fps}$ and stored on the disk simultaneously with ultrasonic 
measurements. PWM signals from ultrasonic sensors and images were simultaneously recorded to the disk. After the measurements, information was retrieved from the ecorded data about open/ closed status of each deposit measuring position.

\subsection{Sprayer Flow Rate Calculation}

The different components and the control system were tested and fine-tuned in the laboratory and on artificial trees; later, when the sprayer prototype was fully assembled, it was tested in the orchard. This process resulted in a real-time system for the continuous separate opening and closing of all three nozzles according to the tree canopy structure. The real-time flow rate of each electro-valve controlled nozzle of the sprayer prototype was computed according to Eq. (9) as follows:

$$
q=p \cdot\left(\frac{a \cdot v \cdot V_{r}}{600 \cdot N}\right),
$$

where $q$ is the real-time flow rate in $1 \mathrm{~min}^{-1} a$ is a constant that considers only one side of the sprayer working width in $\mathrm{m} ; v$ is the speed in $\mathrm{km} \mathrm{h}^{-1} ; V_{\mathrm{r}}$ is the volume application rate for the orchard in 1 ha ${ }^{-1} ; N$ is the number of nozzles; and $p$ is the reduction coefficient of the maximum flow rate given by the following Eq.:

$$
p=\frac{\sum t_{i}}{\sum t},
$$

where $\sum t_{i}$ is the sum of actual opening time for each nozzle, $\sum t$ is the sum of maximum possible opening time for all nozzles.

\subsection{Analysis of Deposit and Spray Coverage}

To analyze the spray deposit two methods were used; Water Sensitive Papers (WSP) and composite leaf samples. WSP measures a number of spray droplets and the percentage of coverage, while leaves samples were used to measure quantity of spray deposit.

In order to quantify the spray deposit and coverage of the drops resulting from different spray modes, Water Sensitive Papers (75 x 26 $\mathrm{mm}$, WSP, Novartis, Switzerland) were placed every time on the same places in each of five trees and three inter-space positions immediately before each spraying as proposed by [1]. The WSP were held by clothespins at fixed positions and were collected approximately $10 \mathrm{~min}$ after they had completely dried.

Data presented are average values of the measurements from upper and lower side of WSP at each specific position. Images of each WSP were digitized using the Optomax Image Analysis system (Optomax, NH, USA), consisting of a CCD camera with a zoom lens, a monitor to control the picture being analyzed, and a $\mathrm{PC}$ with a Frame Grabber card. The area resolution of the system was $1 / 417600$ per field of view $(720 \times$ 580 pixels), so the smallest spot size detected by 1 pixel was $8 \mu \mathrm{m}$ and image depth was 256 grey levels [6]. By using this system, coverage (with stains covered area - \% coverage) the number of impacts and the number of impacts per unit area were all analyzed. Canopy deposits were measured on composite leaf samples, taken from the 12 positions of selected trees in 5 replications so that each sample contained five leaves. The chosen leaves for deposit measurements were held in the same position with clothespins. This ensured exactly the same positions of leaves for both modes of spraying and reduced the variability caused by position of leaves at the points of deposit analysis. After each experiment the leaves were collected from clothespins and placed in plastic bags, taken to the laboratory and stored in a dark and cool place before processing. Tartrazine (Citronin yellow, ETOL, Slovenia), which is often used in spray deposition experiments, was used as a tracer. The concentration of the tracer in the applied spray was $20 \mathrm{~g} 1^{-1}$. Leaf samples were washed with distilled water, shaken in the same plastic bag as collected and the samples of $2 \mathrm{ml}$ were taken for determining the concentration of tartrazine by spectrophotometer Varian CARY 50 BIO. The experimental procedures of [11] followed. Nevertheless, previous tests were made in the laboratory to confirm the accuracy of the methodology, especially in relation to tracer recovery from apple leaf samples, whereby the theoretical and normalised deposit was calculated according to the procedure described by [8]. The tartrazine leaching efficiency was assumed to be $90 \%$. 
All data were transferred from Optomax and Varian to formatted computer spread-sheets (Microsoft Excel) before a statistical analysis of variance ( 2 treatments $\mathrm{x} 5$ repetitions $\mathrm{x} 12$ locations) using the Statgraphics Statistics Package Program.

\section{RESULTS AND DISCUSSION}

\subsection{Reduction of Spray Delivered per Unit Area}

The working time and real-time flow rate of each particular nozzle for a test track is shown in Table 2. The effective working time for each nozzle was calculated as the sum of all opening times from the stored data of the valves' open/closed status during the driving along the track, while the real-time flow rate was calculated according to the driven path and time. The procedure of turning the nozzles on/off was explained in the section 1.4.

Given the average operating time on the $63.76 \mathrm{~m}$ long experimental field track of $53.56 \mathrm{~s}$ per nozzle in the CM, and $42.74 \mathrm{~s}$ with the AM, nozzles were closed on average for $10.82 \mathrm{~s}$; thus calculated spray savings at an average of $20.2 \%$ were achieved for all three nozzles together. For that reason, a significant reduction of the average real-time flow rate per nozzle from $1.451 \mathrm{~min}^{-1}$ to $1.161 \mathrm{~min}^{-1}$ was achieved in comparison with spraying when the sprayer operated in the CM.

The total open time for all three sensors is the same (10.82 s), which means that trees and interspaces were detected in all three heights at the same time. Although the trees were formed in a spindle form with conical shape, the differences in the ratio between dense green wall area and empty space (canopy gaps), which is closely related to the tree height zone, did not affect the average opening time among upper, mid and lower zones, as expected. Thus, further research of other types of ultrasound sensors is planned.

[9] reported $28 \%$ spray saving in a high density pear plantation and $68 \%$ in an older olive plantation, while controlling the sprayer nozzles with ultrasound sensors. In our experiment the spray saving of $20.2 \%$ is good owing to two reasons. First, the canopies in the orchard were more uniformly spread than in olive plantation [9], second, the deposits on targets remained unchanged or they were even higher than in control mode. Thus, for future improvement better performance of ultrasonic transceiver is necessary.

\subsection{Spray Coverage}

The quality of spray distribution determined by the analysis of WSP samples was expressed as the percentage of coverage and the number of impacts per $\mathrm{cm}^{-2}$. As seen from Table 3 in the 'control' repetition the highest coverage (42.39\%) was obtained on the P1 'upper' followed by $\mathrm{P} 3$ and P4. In all tree positions there was no statistically significant difference between the control and automated spraying modes, which means that the reduction of nozzle output during the automated spraying did not significantly reduce the spray coverage. Between trees the highest coverage $(52.81 \%)$ was obtained again on the 'control' P10 'upper' followed by P11 and P12. The same pattern was measured on the automated spraying, which means that common drift between trees could not be prevented significantly by a prototype ultrasound sprayer.

Table 2. Average working time $[\mathrm{s}]$ and real-time flow rate [l $\left.\mathrm{min}^{-1}\right]$ for automated (AM) and control (CM) spray distribution

\begin{tabular}{|c|c|c|c|c|c|c|}
\hline \multirow[b]{2}{*}{$\begin{array}{l}\text { Nozzle } \\
\text { position }\end{array}$} & \multicolumn{3}{|c|}{ Automated (AM) } & \multicolumn{3}{|c|}{ Control (CM) } \\
\hline & $\begin{array}{l}\text { Open time } \\
{[\mathrm{s}]}\end{array}$ & $\begin{array}{c}\text { Close time } \\
{[\mathrm{s}]}\end{array}$ & $\begin{array}{l}\text { Real-time } \\
\text { flow rate } \\
{\left[1 \mathrm{~min}^{-1}\right]}\end{array}$ & $\begin{array}{c}\text { Open time } \\
{[\mathrm{s}]}\end{array}$ & $\begin{array}{c}\text { Close time } \\
{[\mathrm{s}]}\end{array}$ & $\begin{array}{l}\text { Real-time } \\
\text { flow rate } \\
{\left[1 \mathrm{~min}^{-1}\right]}\end{array}$ \\
\hline 1st above & 42.74 & 10.82 & 1.16 & 53.56 & 0.00 & 1.45 \\
\hline $2^{\text {nd }}$ middle & 42.74 & 10.82 & 1.16 & 53.56 & 0.00 & 1.45 \\
\hline 3rd bottom & 42.74 & 10.82 & 1.16 & 53.56 & 0.00 & 1.45 \\
\hline Average & 42.74 & 10.82 & 1.16 & 53.56 & 0.00 & 1.45 \\
\hline Index $\mathrm{A} / \mathrm{C}$ & 0.798 & 0.202 & - & - & - & - \\
\hline
\end{tabular}


Table 3. Comparison between the coverage (\%) in control and automated (AM) spray distribution*

\begin{tabular}{|c|cc|cc|cr|rrr|}
\hline \multirow{2}{*}{ Position } & \multicolumn{4}{|c|}{ Control } & \multicolumn{4}{c|}{ Automated } \\
\cline { 2 - 11 } & \multicolumn{3}{|c|}{ Lower } & \multicolumn{2}{|c|}{ Upper } & \multicolumn{3}{c|}{ Lower } & \multicolumn{3}{c|}{ Upper } \\
\hline P1 & 27.30 & c A & 42.39 & ef $A$ & 30.95 & c A & 41.93 & c $A$ \\
\hline P2 & 17.40 & abc B & 37.34 & def $A$ & 9.56 & ab A & 35.62 & c $A$ \\
\hline P3 & 11.10 & abc B & 39.77 & ef $A$ & 19.87 & abc A & 37.69 & c $A$ \\
\hline P4 & 12.40 & abc A & 34.23 & cde $B$ & 17.27 & abc A & 24.51 & bc $A$ \\
\hline P5 & 12.63 & abc A & 26.59 & bcde A & 7.67 & ab A & 25.90 & bc $A$ \\
\hline P6 & 25.62 & bc B & 33.24 & cde $A$ & 4.85 & ab A & 29.91 & c $A$ \\
\hline P7 & 17.20 & abc A & 10.41 & ab A & 22.45 & abc A & 9.32 & ab A \\
\hline P8 & 5.79 & ab A & 20.54 & abcd $B$ & 5.60 & a A & 9.60 & ab $A$ \\
\hline P9 & 8.75 & ab B & 7.28 & a $A$ & 3.60 & a A & 5.00 & a $A$ \\
\hline P10 & 20.40 & bc B & 52.81 & f $B$ & 7.55 & ab A & 42.00 & c A \\
\hline P11 & 12.60 & abc A & 40.56 & ef $B$ & 7.03 & ab B & 33.01 & c $A$ \\
\hline P12 & 13.67 & abc B & 16.68 & abc $B$ & 1.40 & a A & 8.43 & ab $A$ \\
\hline Lower part of tree & 18.60 & b A & 39.83 & b $A$ & 20.13 & b A & 38.40 & c $A$ \\
\hline Middle part of tree & 16.88 & b A & 31.35 & b $B$ & 9.93 & a $B$ & 26.70 & b $A$ \\
\hline Upper part of tree & 10.59 & a A & 12.74 & a $B$ & 10.55 & a A & 7.97 & a $A$ \\
\hline All tree positions together & 15.35 & b A & 27.97 & a $A$ & 13.54 & b A & 24.39 & a $A$ \\
\hline $\begin{array}{c}\text { All positions between } \\
\text { trees together }\end{array}$ & 15.56 & a B & 36.68 & b $B$ & 5.32 & a A & 227.84 & a $A$ \\
\hline All positions & 15.41 & A & 30.15 & $A$ & 11.48 & A & 25.25 & $A$ \\
\hline
\end{tabular}

Table 4. Comparison between the number of impacts in control and automated (AM) spray distribution*

\begin{tabular}{|c|c|c|c|c|c|c|c|c|}
\hline \multirow{3}{*}{$\begin{array}{c}\text { Position } \\
\text { P1 }\end{array}$} & \multicolumn{4}{|c|}{ Control } & \multicolumn{4}{|c|}{ Automated } \\
\hline & \multicolumn{2}{|c|}{ Lower } & \multicolumn{2}{|c|}{ Upper } & \multicolumn{2}{|c|}{ Lower } & \multicolumn{2}{|c|}{ Upper } \\
\hline & 6 & abc A & & abc $B$ & & $a b c A$ & 89 & ab $A$ \\
\hline P2 & 7 & abc A & 12 & bc $A$ & 6 & abc A & 123 & b $A$ \\
\hline P3 & 8. & abc A & 11 & abc $A$ & 11 & bc B & 115 & $\mathrm{ab} A$ \\
\hline P4 & 7 & abc A & 11 & abc $A$ & 13 & d B & 102 & $\mathrm{ab} A$ \\
\hline P5 & 8. & abc A & 14 & c $A$ & 7 & abcd A & 110 & $\mathrm{ab} A$ \\
\hline P6 & 7. & abc A & 12 & bc $A$ & 9 & abcd A & 112 & ab $A$ \\
\hline P7 & 12 & $\mathrm{cA}$ & 11 & abc A & 11 & bc A & 109 & ab $A$ \\
\hline P8 & & ab B & 13 & c $B$ & 4 & $\mathrm{ab} \mathrm{A}$ & 85 & $\mathrm{ab} A$ \\
\hline P9 & 5 & $\mathrm{ab} \mathrm{A}$ & 7 & $\mathrm{ab} A$ & & a B & 68 & a $A$ \\
\hline P10 & & bc A & 7 & a $A$ & & abcd A & 102 & ab $B$ \\
\hline P11 & & $\mathrm{ab} \mathrm{A}$ & 10 & abc $A$ & 10 & bcd B & 122 & $\mathrm{~b} \mathrm{~A}$ \\
\hline P12 & 2. & a A & 7 & ab $A$ & & abcd B & 81 & ab $A$ \\
\hline Lower part of tree & 7 & $\mathrm{a} \mathrm{A}$ & 11 & a $\mathrm{A}$ & 8 & $\mathrm{ab} A$ & 109 & b $A$ \\
\hline Middle part of tree & 7 & a $\mathrm{A}$ & 12 & a $A$ & 10 & b B & 107 & b $A$ \\
\hline Upper part of tree & 8 & a $B$ & 10 & a $B$ & 6 & a $\mathrm{A}$ & 87 & a $A$ \\
\hline All tree positions together & 7 & b A & 11 & b $A$ & & a $\mathbf{A}$ & 101 & a $A$ \\
\hline $\begin{array}{l}\text { All positions between } \\
\text { trees together }\end{array}$ & & a $\mathbf{A}$ & & a $\boldsymbol{A}$ & 8 & a $\mathbf{B}$ & 102 & a $\mathbf{B}$ \\
\hline All positions & 7 & A & 10 & $A$ & & A & 101 & $A$ \\
\hline
\end{tabular}

\footnotetext{
*Notes: abc ... differences between positions on the tree (Tukey HSD test; $\alpha=0.05$ ), A, B difference between Control and Automated spraying mode (t-test; $\alpha=0.05)$, A, B comparisons of positions inside the tree and between trees ( $\mathrm{t}$-test; $\alpha=0.05$ )
} 
However, in both modes there was significantly higher coverage in the upper than on the lower side of WSP in all positions, except in case of positions $\mathrm{P} 7$ and $\mathrm{P} 12$, which is commonly known spray pattern for the axial fan mistblower. Additional comparison of summarized data showed that the coverage was the lowest in the upper part of tree $(12.7 \%$ control and $7.97 \%$ automated), which significantly differs from the middle (31.3\% control and $26.7 \%$ automated), and lower part of the tree (39.8\% control and $38.4 \%$ automated). The same distribution was detected in both spraying modes; however there was no statistically significant difference between them, which means that the newer technique assured the same quality of spray coverage as the standard one.

The number of impacts per $\mathrm{cm}^{-2}$ is presented in Table 4. It can be seen that the highest number of impacts (146) was detected in the 'control mode' on the P5 followed by P8 (132) and P2 (123). In AM the highest number of impacts (123) was again detected in P2 followed by P3 (115) and P6 (112). However, a decrease of impact numbers was detected on the WSPs lower facing, which could be connected to the fast pulse opening and closing of nozzles leading to a reduction of the droplet size. Although the use of automated system reduced the determined number of droplet impacts in all from 108 to 101 (see Table 4), there was no significant difference of the coverage values when the sprayer was operated in AM.

\subsection{Spray Deposition}

The quality of spray distribution determined by spectrophotometric measurements

Table 5. Comparison between the tartrazine tracer deposit $\left[\mu \mathrm{g} / \mathrm{cm}^{2}\right]$ in control and automated (AM) spray distribution

\begin{tabular}{|c|c|c|c|c|c|c|c|c|}
\hline \multirow{3}{*}{$\begin{array}{c}\text { Position } \\
\text { P1 }\end{array}$} & \multicolumn{3}{|c|}{ Control } & \multicolumn{5}{|c|}{ Automated } \\
\hline & $\begin{array}{c}\text { Measured } \\
\text { deposit } \\
{\left[\mu \mathrm{g} / \mathrm{cm}^{2}\right]}\end{array}$ & \multicolumn{2}{|c|}{$\begin{array}{c}\text { Normalised } \\
\text { deposit* }^{*}\end{array}$} & $\begin{array}{c}\text { Measured } \\
\text { deposit } \\
{\left[\mu \mathrm{g} / \mathrm{cm}^{2}\right]}\end{array}$ & \multicolumn{2}{|c|}{$\begin{array}{c}\text { Normalised } \\
\text { deposit* }^{*}\end{array}$} & \multicolumn{2}{|c|}{$\begin{array}{c}\text { Corrected } \\
\text { normalised } \\
\text { deposit** }\end{array}$} \\
\hline & 5.15 bc A & 0.70 & $\mathrm{~A}$ & $5.14 \mathrm{~cd} \mathrm{~A}$ & 0.69 & A & 0.86 & $\mathrm{~A}$ \\
\hline P2 & 4.11 abc A & 0.56 & A & $3.38 \mathrm{abc} \mathrm{A}$ & 0.46 & A & 0.58 & A \\
\hline P3 & 6.01 & 0.81 & A & 4.46 bcd A & 0.60 & A & 0.75 & A \\
\hline P4 & 3.79 abc A & 0.51 & $\mathrm{~A}$ & 3.60 abc A & 0.49 & A & 0.61 & $\mathrm{~A}$ \\
\hline P5 & 3.71 abc A & 0.50 & A & 3.17 abc A & 0.43 & A & 0.54 & $\mathrm{~A}$ \\
\hline P6 & 3.55 abc A & 0.48 & A & 3.54 abc A & 0.48 & A & 0.60 & $\mathrm{~A}$ \\
\hline P7 & 1.59 & 0.21 & $\mathrm{~A}$ & $2.26 \quad \mathrm{ab} \mathrm{A}$ & 0.31 & $\mathrm{~A}$ & 0.39 & $\mathrm{~A}$ \\
\hline P8 & ab A & 0.30 & A & 1.87 & 0.25 & A & 0.31 & $\mathrm{~A}$ \\
\hline P9 & 2.03 & 0.27 & $\mathrm{~A}$ & 1.67 & 0.23 & A & 0.29 & $\mathrm{~A}$ \\
\hline P10 & 6.35 & 0.86 & A & 6.09 & 0.82 & A & 1.03 & $\mathrm{~A}$ \\
\hline P11 & bc A & 0.70 & A & $\mathrm{cd} \mathrm{A}$ & 0.71 & $\mathrm{~A}$ & 0.89 & $\mathrm{~A}$ \\
\hline P12 & 1.85 & 0.25 & $\mathrm{~A}$ & 1.58 & 0.21 & A & 0.26 & $\mathrm{~A}$ \\
\hline Lower tree & 5.09 & 0.69 & $\mathrm{~A}$ & 4.33 & 0.59 & $\mathrm{~A}$ & 0.74 & $\mathrm{~A}$ \\
\hline Middle tree & 3.68 & 0.50 & $\mathrm{~A}$ & 3.44 & 0.46 & $\mathrm{~A}$ & 0.58 & A \\
\hline Upper tree & 1.94 & 0.26 & $\mathrm{~A}$ & 1.93 & 0.26 & A & 0.33 & $\mathrm{~A}$ \\
\hline All on the tree & A $A$ & 0.48 & A $A$ & A $A$ & 0.44 & A $A$ & 0.55 & A $A$ \\
\hline All between trees & A $A$ & 0.59 & A $A$ & A $B$ & 0.59 & A $B$ & 0.74 & A $B$ \\
\hline All positions & 3.77 & 0.51 & $\mathrm{~A}$ & 3.52 & 0.48 & $\mathrm{~A}$ & 0.60 & $\mathrm{~A}$ \\
\hline
\end{tabular}

Notes: ${ }^{*} 7.4 \mu \mathrm{g} / \mathrm{cm}^{2}=1=100 \%$ of theoretical deposit $1, \quad * * 5.9 \mu \mathrm{g} / \mathrm{cm}^{2}=1=100 \%$ of theoretical deposit 2 , Normalised deposit $=$ measured deposit / theoretical deposit ${ }^{*},{ }^{*}$ Theoretical deposit $1=\left(\right.$ applied hectare tracer rate at control mode $\left(\mathrm{g} / \mathrm{m}^{2}\right) /$ orchard leaf area $\left.\mathrm{m}^{2}\right),{ }^{*}$ Theoretical deposit $2=\left(\right.$ applied hectare tracer rate at automated mode $\left(\mathrm{g} / \mathrm{m}^{2}\right) /$ orchard leaf area $\left.\mathrm{m}^{2}\right)$, abc ... differences between positions on the tree (Tukey HSD test; $\alpha=0.05$ ), A, B difference between Control and Automated spraying mode (t-test; $\alpha=0.05), A, B$ comparisons of positions inside the tree and between trees ( $t$-test; $\alpha=0.05$ ) 
of tartrazin deposits on the leaf samples was expressed in $\mu \mathrm{g} / \mathrm{cm}^{2}$ as well as in form of normalized deposit, whereby the maximum theoretical deposit amounting $7.4 \mu \mathrm{g} / \mathrm{cm}^{2}$ is assumed as $1(100 \%)$ in control mode and 5.9 $\mu \mathrm{g} / \mathrm{cm}^{2}$ in AM. The difference in the theoretical starting-points of both modes is due to the $79.8 \%$ nozzles opening time during AM.

As seen from the Table 5 'control' the highest deposit $\left(6.35 \mu \mathrm{g} / \mathrm{cm}^{2}\right)$ was detected on lower inter tree position P10 followed by $\mathrm{P} 3$ and $\mathrm{P} 1$. In all upper tree positions (P7 to P9) there was a significantly lower deposit measured than in the middle and lower positions, which means that a relevant loss of spray appeared in this part of trees.

In AM the highest deposit $\left(6.09 \mu \mathrm{g} / \mathrm{cm}^{2}\right)$ was again detected on lower inter tree position P10 (Fig. 5), the second highest position was the middle inter tree position P11 $\left(5.23 \mu \mathrm{g} / \mathrm{cm}^{2}\right)$ and the lower outer position P1. Although the overall deposit reached $3.52 \mu \mathrm{g} / \mathrm{cm}^{2}$ of leaf area in $\mathrm{AM}$, which is for about $10 \%$ lower than in case of control mode $\left(3.77 \mu \mathrm{g} / \mathrm{cm}^{2}\right)$, the corrected normalized deposit was in fact by $9 \%$ higher (see Table 5 automated). Despite the 20.2\% spray savings, due to a lower amount of spray flow through the nozzles, only $10 \%$ less spray was deposited on the leaves and the differences between positions were lower). At the same time a higher normalised deposit was detected.

This can be seen in the position P10 (1.03), P11 (0.89) and P1 (0.86), where values of normalised deposit did not differ statistically from the CM. From these results it can be concluded that the spray deposition quality in the $\mathrm{AM}$ is totally comparable to the one of the CM.

Table 5. Comparison between the tartrazine tracer deposit $\left[\mu \mathrm{g} / \mathrm{cm}^{2}\right]$ in control and automated (AM) spray distribution

\begin{tabular}{|c|c|c|c|c|c|c|c|c|}
\hline \multirow{3}{*}{$\begin{array}{c}\text { Position } \\
\text { P1 }\end{array}$} & \multicolumn{3}{|c|}{ Control } & \multicolumn{5}{|c|}{ Automated } \\
\hline & $\begin{array}{c}\text { Measured } \\
\text { deposit } \\
{\left[\mu \mathrm{g} / \mathrm{cm}^{2}\right]}\end{array}$ & \multicolumn{2}{|c|}{$\begin{array}{c}\text { Normalised } \\
\text { deposit* }^{*}\end{array}$} & $\begin{array}{c}\text { Measured } \\
\text { deposit } \\
{\left[\mu \mathrm{g} / \mathrm{cm}^{2}\right]}\end{array}$ & \multicolumn{2}{|c|}{$\begin{array}{c}\text { Normalised } \\
\text { deposit* }\end{array}$} & \multicolumn{2}{|c|}{$\begin{array}{l}\text { Corrected } \\
\text { normalised } \\
\text { deposit** }\end{array}$} \\
\hline & 5.15 bc $A$ & 0.70 & $\mathrm{~A}$ & $5.14 \quad \mathrm{~cd} \mathrm{~A}$ & 0.69 & $\mathrm{~A}$ & 0.86 & $\mathrm{~A}$ \\
\hline P2 & 4.11 abc $A$ & 0.56 & A & $3.38 \quad a b c$ A & 0.46 & $\mathrm{~A}$ & 0.58 & A \\
\hline $\mathrm{P} 3$ & $6.01 \quad \mathrm{c} \mathrm{A}$ & 0.81 & $\mathrm{~A}$ & 4.46 bcd A & 0.60 & $\mathrm{~A}$ & 0.75 & $\mathrm{~A}$ \\
\hline P4 & 3.79 abc A & 0.51 & A & 3.60 abc A & 0.49 & $\mathrm{~A}$ & 0.61 & $\mathrm{~A}$ \\
\hline P5 & 3.71 abc A & 0.50 & $\mathrm{~A}$ & 3.17 abc $\mathrm{A}$ & 0.43 & $\mathrm{~A}$ & 0.54 & $\mathrm{~A}$ \\
\hline P6 & 3.55 abc $A$ & 0.48 & $\mathrm{~A}$ & 3.54 abc A & 0.48 & $\mathrm{~A}$ & 0.60 & $\mathrm{~A}$ \\
\hline P7 & a A & 0.21 & A & $2.26 \quad \mathrm{ab} \mathrm{A}$ & 0.31 & $\mathrm{~A}$ & 0.39 & A \\
\hline $\mathrm{P} 8$ & $\mathrm{ab} \mathrm{A}$ & 0.30 & $\mathrm{~A}$ & a A & 0.25 & $\mathrm{~A}$ & 0.31 & $\mathrm{~A}$ \\
\hline P9 & 2.03 & 0.27 & $\mathrm{~A}$ & 1.67 & 0.23 & $\mathrm{~A}$ & 0.29 & $\mathrm{~A}$ \\
\hline P10 & 6.35 & 0.86 & $\mathrm{~A}$ & 6.09 & 0.82 & $\mathrm{~A}$ & 1.03 & $\mathrm{~A}$ \\
\hline P11 & bc A & 0.70 & $\mathrm{~A}$ & $\operatorname{cd~A}$ & 0.71 & $\mathrm{~A}$ & 0.89 & $\mathrm{~A}$ \\
\hline P12 & $\mathrm{a} \mathrm{A}$ & 0.25 & $\mathrm{~A}$ & 1.58 & 0.21 & $\mathrm{~A}$ & 0.26 & A \\
\hline Lower tree & 5.09 & 0.69 & $\mathrm{~A}$ & 4.33 & 0.59 & $\mathrm{~A}$ & 0.74 & $\mathrm{~A}$ \\
\hline Middle tree & 3.68 & 0.50 & $\mathrm{~A}$ & 3.44 & 0.46 & $\mathrm{~A}$ & 0.58 & $\mathrm{~A}$ \\
\hline Upper tree & 1.94 & 0.26 & $\mathrm{~A}$ & 1.93 & 0.26 & $\mathrm{~A}$ & 0.33 & $\mathrm{~A}$ \\
\hline All on the tree & A $A$ & 0.48 & $A$ & A $A$ & 0.44 & A $A$ & 0.55 & A $A$ \\
\hline All between trees & A $A$ & 0.59 & $A$ & A $B$ & 0.59 & A $B$ & 0.74 & A $B$ \\
\hline All positions & 3.77 & 0.51 & $\mathrm{~A}$ & 3.52 & 0.48 & $\mathrm{~A}$ & 0.60 & $\mathrm{~A}$ \\
\hline
\end{tabular}

Notes: $* 7.4 \mu \mathrm{g} / \mathrm{cm}^{2}=1=100 \%$ of theoretical deposit $1, \quad * * 5.9 \mu \mathrm{g} / \mathrm{cm}^{2}=1=100 \%$ of theoretical deposit 2 ,

Normalised deposit $=$ measured deposit $/$ theoretical deposit, ${ }^{*}$ Theoretical deposit $1=$ (applied hectare tracer rate at control mode $\left(\mathrm{g} / \mathrm{m}^{2}\right) /$ orchard leaf area $\left.\mathrm{m}^{2}\right),{ }^{*}$ Theoretical deposit $2=\left(\right.$ applied hectare tracer rate at automated mode $\left(\mathrm{g} / \mathrm{m}^{2}\right) /$ orchard leaf area $\mathrm{m}^{2}$ ), abc ... differences between positions on the tree (Tukey HSD test; $\alpha=0.05$ ), A, B difference between Control and Automated spraying mode (t-test; $\alpha=0.05)$, A, B comparisons of positions inside the tree and between trees (t-test; $\alpha=0.05)$ 


\section{CONCLUSIONS}

Assessment of ultrasonic electronic control system for proportional spray application showed a total of $20.2 \%$ saving of spray per nozzle and area unit (0.30 $1 \mathrm{~min}^{-1}$ flow rate reduction) when used in $\mathrm{AM}$, in comparison to spraying in $\mathrm{CM}$. This saving was achieved without significant reduction of spray coverage at any tree positions making the approach interesting for further developments. However, this is not enough to claim the same spray savings for diverse spraying applications in a number of orchards, planted with different fruit varieties with trees of varying training systems and size.

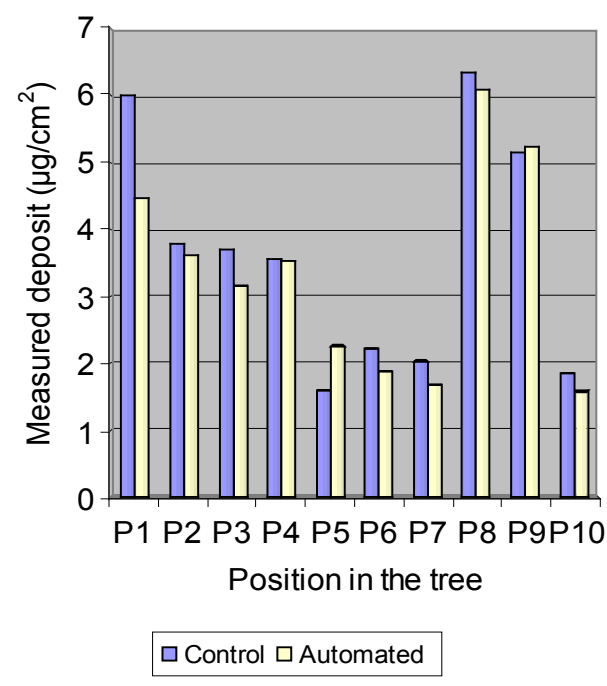

Fig. 5. Measured tartrazine tracer deposit on the different tree position

Three ultrasonic sensors and three nozzles were used in our experiments. In practice, it would be better to have more electro-valve controlled nozzles with a narrower working angle, because in that case the ability of adapting of the individual nozzle output to the characteristics of the tree canopy zones (ratio between green wall area and canopy gaps) would be better.

The novel design of automated sprayer with ultrasonic sensors can bring progress in spraying plantations with a number of orchards of different training systems and age. For instance, especially in the case of smaller trees in young plantations the upper nozzle can be switched off; or in the varying tree structure the opening/closing of nozzles can be adapted automatically.

It is well known that in the present development stage ultrasonic sensors can not distinguish very small and dense structures of the canopy, orchard supports and broad less dense canopies. For this reason and for the reason that most of the ultrasonic echo is formed on the canopy outer layer, the ultra sound sprayer guidance system operated by standard ultrasonic sensors, unlike the radar guidance systems, is not able to provide the information about the tree structure deep inside the tree crown.

Sensors detection should be evaluated regarding the tree structure and canopy properties. Sensors used in this experiment, provided only information in the form of presence of the target and its distance. Small very dense targets performed similar to large less dense targets. There might exist an opportunity for a further upgrade of sensors electronics to distinguish between both mentioned cases. Potential further improvement of our prototype system can be achieved by modifying the ultrasonic sensors so they could detect the tree structure selectively according to the different reflection from the leaf density in the middle of the crown and give a better discrimination of tree crown and the background also in the lower section of trees.

\section{ACKNOWLEDGEMENTS}

This research was funded by ARRS No. 3211-10-000040 as part a of EUREKA project. The funding is gratefully acknowledged. The authors also acknowledge the vital contributions made by the following colleagues: Stanislav Vajs, who was responsible for the field measurements; technician and tractor driver, Toni Gjergek; and Roman Mauc, the head of the experimental orchard in Brdo pri Lukovici, who was always willing to help during the measurements in the orchard; and to Professor Michelle Gadpaille, for her editing of the manuscript.

\section{REFERENCES}

[1] Cross, J.V., Walklate, P.J., Murray, R.A., Richardson, G.M. (2001). Spray deposits and losses in different sized apple trees from 
an axial fan orchard sprayer: 1. effects of spray liquid flow rate. Crop Protection, vol. 20, p. 13-30.

[2] Eberlinc, M., Dular, M., Širok, B., Lapanja, B. (2008). Influence of blade deformation on integral characteristic of axial flow fan. Strojniški vestnik - Journal of Mechanical Engineering, vol. 54, no. 3, p. 159-169.

[3] Byers, R.E., Hickey, K.D., Hill, C.H. (1971): Base Gallonage Per Acre. Virginia Fruit, vol. 60 , p. 19-23.

[4] Heijne, B., Doruchowski, R., Hołownicki, Koch, H., Jaeken, P., Siegfried, W., Hollinger, E. Cross, J.V., Orts, R. (1997). Developments in spray application techniques in European pome fruit growing. IOBC/WPRS Bull., vol. 20, no. 9, p. 119129.

[5] Sutton, T.B., Unrath, C.R. (1984). Evaluation of the tree-row-volume concept with density adjustments in relation to spray deposits in apple orchards. Plant Disease, vol. 68 , p. 480-484.

[6] Sutton, T.B., Unrath, C.R. (1988). Evaluation of the tree-row-volume model for full-season pesticide application on apples. Plant Disease, vol. 72, p. 629-632.

[7] Pergher, G., Gubiani, R., Tonetto, G. (1997). Foliar deposition and pesticide losses from three air-assisted sprayers in a hedgerow vineyard. Crop Protection, vol. 16, p. 25-33.

[8] Pergher, G., Petris, R. (2008). Pesticide dose adjustment in vineyard spraying and potential for dose reduction. The Cigr Ejournal, 10, Manuscript Alnarp 08 011, vol. X.

[9] Solanelles, F., Escolà, A., Planas, S., Rosell, J.R., Camp, F., Gràcia, F. (2006). An Electronic control system for pesticide application proportional to the canopy width of tree crops. Biosystems Engineering, vol. 95, p. 473-481.

[10] Wangler, R.J., Connell, R.E., Fowler, K.L., Olson, R.A. (1993). Application of smart submunition technology to agribusiness. J.A. Deshazer, Meyer, G.E. (eds.). Proc. Spie Optics In Agriculture And Forestry, vol. 1836, p. 261-272.

[11] Walklate, P.J., Cross, J.V., Richardson, G.M., Murray, R.A., Baker, D.E. (2002). Comparison of different spray volume deposition models using lidar measurements of apple orchards. Biosystems Engineering, vol. 82 , p. 253-267.

[12] Gil, E., Escolà, A., Rosell, J.R., Planas, S., Val, L. (2007). Variable rate application of plant protection products in vineyard using ultrasonic sensors. Crop Protection, vol. 26, p. 1287-1297.

[13] Moltó, E., Martín, B., Gutiérrez, A. (2000). Design and testing of an automatic machine for spraying at a constant distance from the tree canopy. Journal of Agricultural Engineering Research, vol. 77, p. 379-384.

[14] Hołownicki, R., Doruchowski, G., Świechowski, W., Jaeken, P. (2002). Methods of evaluation of spray deposit and coverage on artificial targets. Electronic Journal of Polish Agricultural Universities, from: http://www.ejpau.media.pl/volume5/ issuel/engineering/art-03.html, accessed on 2010-09-11.

[15] Moltó, E., Martín, B., Gutiérrez, A. (2000). Pesticide loss reduction by automatic adoption of spraying on globular trees. Journal of Agricultural Engineering Research, vol. 78, p. 35-41.

[16] Pergher, G. (2001). Recovery rate of the tracer days used for spray deposit assessment. Transactions of ASABE, vol. 44, no. 4, p. 787-794. 